\title{
A DITADURA CIVIL-MILITAR E A DEMOCRACIA NO PARANÁ NA PERSPECTIVA DA EDUCAÇÃO HISTÓRICA
}

\section{THE CIVILIAN-MILITARY DICTATORSHIP AND DEMOCRACY IN THE STATE OF PARANÁ IN THE HISTORICAL EDUCATION PERSPECTIVE}

\author{
Ana Claudia Urban ${ }^{1}$ \\ Geraldo Becker ${ }^{2}$
}

\begin{abstract}
RESUMO: Este trabalho de pesquisa de pesquisa ${ }^{3}$ busca por meio do estudo de um caso apontar algumas reflexões sobre o processo de ensino e aprendizagem em História. Para tanto, buscou no aporte teórico e metodológico da Educação Histórica e na teoria da consciência histórica de Jörn Rüsen, subsídios para analisar e categorizar os conhecimentos apresentados por 23 estudantes, cursando a $3^{a}$ série do Ensino Médio de um colégio da região Leste da cidade Curitiba-PR, sobre o tema Ditadura civil-militar e a Democracia no Paraná. A pesquisa foi de cunho qualitativo e a ação principal foi o trabalho multiperspectivado por meio de fontes históricas diversificadas, demonstrando assim, novas possibilidades para o estudo da história local por intermédio da pluralidade de interpretações e explicações sobre o passado e o presente.
\end{abstract}

Palavras-chave: Ensino e aprendizagem. Educação Histórica. Consciência Histórica. Conhecimentos prévios. História local.

\begin{abstract}
: this research intends, by studying one case, to point out some reflections on the process of teaching and learning in the subject of History. For that to be accomplished, contribution from Historical Education theory and methodology as well as Jörn Rüsen's theory of Historical Consciousness were used, in order to analyze and categorize the works presented by 23 Senior High School students from a high school located in the East side of the city of Curitiba, in the state of Paraná, on the Civilian-Military Dictatorship and Democracy in the State of Paraná. The research was a qualitative one and the main action was the multiperspective work from diversified historical sources, demonstrating then, new possibilities to study the local history through the plurality of interpretations and explanations of the past and present.
\end{abstract}

Keywords: Teaching and learning. Historical Education. Historical Consciousness. Previous knowledge. Local history.

1 Doutora em Educação. Professora da Universidade Federal do Paraná - Setor de Educação. Professora do Programa de Pós-Graduação em Educação, do Mestrado Profissional em Ensino de História e Professora de Metodologia e Prática de Docência de História. Pesquisadora do Laboratório de Pesquisa em Educação Histórica (LAPEDUH - UFPR). ORCID ID: https://orcid.org/0000-0001-9957-8838. E-mail: claudiaurban@uol.com.br

2 Professor de História das redes estadual e privada do Estado do Paraná. Mestre em Educação pela Universidade Federal do Paraná - UFPR, Pesquisador do Laboratório de Pesquisa em Educação Histórica (LAPEDUH - UFPR), Bolsista CAPES/PROEX. ORCID ID: https://orcid.org/0000-00032455-9469. E-mail: beckergeral@gmail.com

3 O presente trabalho foi realizado com apoio da Coordenação de Aperfeiçoamento de Pessoal de Nível Superior - Brasil (CAPES/PROEX) - Código de Financiamento 001. 


\section{Introdução}

Este trabalho busca discutir o processo de ensino e aprendizagem em História na perspectiva da escola vista como um espaço de produção de conhecimentos e não somente de reprodução. Neste sentido, apresenta algumas reflexões por meio do estudo de um caso realizado com um grupo de 23 estudantes na faixa etária entre 16 e 18 anos, cursando a $3^{a}$ série do Ensino Médio, de um colégio da região Leste da capital paranaense sobre o conteúdo substantivo ${ }^{4}$ Ditadura civil-militar e a Democracia no Paraná.

A pesquisa surge após dois acontecimentos que marcaram a história do Brasil no início do ano de 2015, o primeiro relacionado com as manifestações ocorridas em algumas regiões do território brasileiro no dia 15 de março contra o governo de Dilma Rousseff (PT) - eleita pelo processo democrático - e a favor de uma intervenção militar e da volta das forças armadas ao poder.

O segundo, após o episódio do dia 29 de abril de 2015, ocorrido na Praça Nossa Senhora de Salete, em Curitiba - PR, no qual, professores e funcionários públicos do Estado do Paraná, foram massacrados pela ação violenta da polícia militar e pela política autoritária do governador Carlos Alberto Richa. As agressões sofridas pelos servidores nesse evento ocorreram devido a protestos contra o descumprimento de acordo firmado entre o governo deste Estado e os servidores públicos no dia 9 de março de 2015 - depois de 29 dias de greve sobre um conjunto de medidas que ficou conhecido como "Pacotão ou Pacotaço", em que o ponto central era a discussão sobre a reforma previdenciária dos servidores.

Com a repercussão destes episódios nas mídias (televisão, rádio, internet entre outros), alguns estudantes que cursavam a $3^{a}$ série do Ensino Médio do colégio que eu trabalhava queriam saber qual era a minha posição em relação às manifestações pedindo uma intervenção militar contra o governo de Dilma Rousseff e as agressões sofridas pelos professores e funcionários públicos do Estado do Paraná.

\footnotetext{
${ }^{4}$ Para Schmidt, Silva e Cainelli (2019, p 10) conteúdos substantivos estão relacionados com os conteúdos de história, ou seja, o que conhecemos do passado em forma de datas, dados, conceitos, personagens e acontecimentos.
} 
A partir destes questionamentos falei que não iria dar minha opinião sem antes realizarmos um trabalho de pesquisa em conjunto, pois eu não queria influenciar o ponto de vista deles. Nesse momento percebi que poderia desenvolver uma investigação sobre o processo de ensino e aprendizagem em história, pautado na relação entre a vida prática dos estudantes e a ciência da história, ou seja, o ponto de partida seria os conhecimentos que os jovens estudantes possuíam sobre o período em que o Brasil foi governado pelos militares e especificamente o que e como eles sabiam sobre esta temática no Paraná, pois segundo Lee:

Há mais na história do que somente acúmulo de informações sobre o passado. O conhecimento escolar do passado e atividades estimulantes em sala de aula são inúteis se estiverem voltadas somente à execução de ideias de nível muito elementar, como que tipo de conhecimento é a história, e estão simplesmente condenadas a falhar se não tomarem como referência os préconceitos que os alunos trazem para suas aulas de história (LEE, 2006, p. 136).

Nesse sentido, pensar o ensino e a aprendizagem em História, é ver a escola como um espaço de criação de conhecimentos e não somente de reprodução. Para tanto busquei por meio do aporte teórico e metodológico da Educação Histórica, da teoria da consciência histórica de Jörn Rüsen e dos princípios éticos das pesquisas de natureza qualitativa, problematizar e provocar conflitos cognitivos nos estudantes, levando-os a discutir e a refletir sobre algumas questões referentes à intervenção militar no Brasil, a volta das forças armadas ao poder e o massacre desenvolvido pela ação violenta da polícia militar e da política autoritária do governador Carlos Alberto Richa.

Desta forma, a pesquisa foi desenvolvida em 4 (quatro) momentos. O primeiro buscou investigar, analisar e sistematizar os conhecimentos presentes nas narrativas produzidas pelos estudantes após a apresentação de um instrumento de pesquisa contendo 2 (duas) fontes iconográficas e uma questão para a construção de uma narrativa.

No segundo momento foi realizado um processo de intervenção pedagógica por meio da problematização de fontes historiográficas com diferentes perspectivas, no qual foram apresentados 2 (dois) artigos que 
discutiam de forma divergente os conceitos Ditadura militar e Ditadura civilmilitar. Em relação ao período da Ditadura no Paraná, foram apresentados 3 (três) documentários que demonstravam a repressão desenvolvida por esta forma de governo e a resistência dos professores e do movimento estudantil da Universidade Federal do Paraná no período de 1964 a 1985.

Quanto ao terceiro momento, foi solicitado aos estudantes que formassem equipes composta de 4 (quatro) integrantes e se organizassem para a produção de pequenos vídeos documentários, que discutissem questões referentes a forma de governo no Brasil no período de 1964 a 1985.

No último momento, busquei entender a consciência histórica dos estudantes a respeito dos conceitos Ditadura militar e Ditadura civil-militar, como eles discutiam esta forma de governo e como eles relacionavam com a questão Democracia no Paraná.

\section{Referencial teórico metodológico: pressupostos da investigação}

A possibilidade de novos paradigmas para o ensino de História no Brasil passa a ser pensada a partir de meados da década de 1980, quando ocorrem debates e discussões sobre as concepções e metodologias de ensino e a disciplina de história "como espaço para um ensino crítico, centrado em discussões sobre temáticas relacionadas com o cotidiano do aluno, seu trabalho e sua historicidade" (SCHMIDT; CAINELLI, 2004, p. 12-13).

A partir desse momento, vários pesquisadores passam a desenvolver seus trabalhos a procura de elementos que constituem o processo de ensino e aprendizagem em História, pautado na Teoria e na Filosofia da História, ou seja, na própria ciência de referência e seu ensino específico. Neste sentido, segundo Germinari (2010, p. 20) estas investigações em cognição histórica, também denominada Educação Histórica buscam entender as ideias históricas dos estudantes com o enfoque em 3 (três) núcleos: "a) análise sobre ideias de segunda ordem; b) análise relativas às ideias substantivas; c) reflexões sobre o uso do saber histórico." Para esse autor: 
As pesquisas sobre ideias de segunda ordem buscam compreender o pensamento histórico segundo critérios de qualidade, ancorado nos debates contemporâneos sobre a filosofia e teoria da História. Nesse enfoque não interessam as questões relativas á quantidade ou simples correção de informações factuais sobre o passado, mas as questões relacionadas ao raciocínio e a lógica histórica. A análise de ideias substantivas concentradas em reflexões sobre os conceitos históricos, envolve noções gerais (revolução, imigrações...) e noções particulares relativas a contextos específicos no tempo e no espaço (exemplo: histórias nacionais, regionais e locais). Estas análises também utilizam critérios de qualidade destacando valores e motivações associados aos conceitos substantivos da História. As investigações sobre o uso do saber histórico analisam questões relativas ao significado e uso da História na vida cotidiana (GERMINARI, 2010, p. 20).

Nesta perspectiva, o raciocínio, a forma de pensar, o significado e o uso da História para a vida, são questões norteadoras da aprendizagem histórica, para Rüsen (1993, p. 52) esta aprendizagem é "a consciência humana relacionada ao tempo, analisando o tempo para ser significativo, adquirindo a competência de dar sentido (significado) ao tempo e desenvolver esta competência". Desse modo, pensar a aprendizagem histórica requer uma compreensão de que existe uma cognição específica situada na ciência da História, ou seja, "a forma pela qual o conhecimento necessita ser aprendido pelo aluno deve ter como base a própria racionalidade histórica, e os processos cognitivos devem ser os mesmos da própria epistemologia da ciência da História" (SCHMIDT, 2009, p. 29).

Assim pode-se pensar em um domínio teórico específico conceituado como Didática da História, vista como a ciência da aprendizagem histórica, pois "produz de modo científico (especializado) o conhecimento necessário e próprio à história, quando se necessita compreender os processos de aprendizagem e lidar com eles de modo competente." Desta forma, esse processo mental específico acontece a partir do entendimento dos métodos e formas de trabalhar com experiências do passado, "pois é somente por intermédio desses processos que o passado se torna história" (RÜSEN, 2015, p. 248- 249).

A partir desses pressupostos Maria Auxiliadora Schmidt (2017, p. 62) aponta que

As reflexões de Jörn Rüsen, ao trazerem o pressuposto da Didática como a ciência da aprendizagem histórica, sinalizam que a questão central é compreender como o pensamento histórico contribui para 
orientar, temporalmente, a vida humana para dentro (identidade) e para fora (práxis). Do ponto de vista epistemológico, a Didática da História presta contas com o processo do aprender a pensar historicamente, ou seja, com realizar a 'formação histórica' e isto envolve dois aspectos - vida prática e ciência - organicamente interligados. Numa perspectiva transversal, significa entender o saber histórico como síntese da experiência humana com a sua interpretação para orientação na vida prática; e na horizontal, seria considerar a formação como socialização e individuação (dinâmica da identidade histórica) a partir de sua relação com a ciência.

Neste sentido, a autora apresenta um estudo sobre a matriz da Didática da História ${ }^{5}$ de Jörn Rüsen, no qual discute o processo de ensino e aprendizagem pautado na relação entre a "vida prática dos sujeitos - professores e alunos - e a ciência da história". Segundo suas reflexões, o ponto de partida deve ser as carências e os interesses apresentados pelos sujeitos, pois são eles que

[...] indicam a ida às teorias da aprendizagem, depositárias dos conceitos históricos, sejam eles substantivos (relacionados aos conteúdos da história), ou epistemológicos (relacionados aos processos cognitivos do pensamento histórico, tais como evidência e explicação histórica) (SCHMIDT, 2017, p. 63).

Ainda segundo a autora, na relação ensino e aprendizagem o percurso deve ser o mesmo constitutivo da produção do conhecimento histórico e o trabalho com fontes históricas é fundamental como princípio do método de ensino, pois é a partir dele que o passado passa a ser interpretado e expressado por meio da narrativa histórica (SCHMIDT, 2017, p. 63-64).

Mas o que é uma narrativa histórica? Segundo Jörn Rüsen (2015, p. 81), uma narrativa é histórica "quando exprime o contexto temporal que articula sistematicamente a interpretação do passado com um entendimento do presente e as expectativas de futuro". Ainda segundo este autor, a narrativa histórica pode ser vista como uma operação mental da consciência histórica e é por meio dela que particularidade e processualidade desta consciência "podem ser explicitadas didaticamente e constituídas como uma determinada construção de sentido sobre a experiência do tempo" (RÜSEN, 2011, p. 43).

\footnotetext{
${ }^{5}$ Schmidt (2017)
} 
Desta forma, o processo de ensino e aprendizagem em História deve estar pautado na própria ciência de referência, assim como também na valorização dos conhecimentos que os estudantes possuem, pois é a partir destes pressupostos que o "ensino e a História encontram seu sentido na vida prática humana" (SCHMIDT, 2017, p. 68).

\section{Categorização dos conhecimentos prévios}

Buscando perceber qual a consciência de referência ligada à vida prática sobre o conceito substantivo Ditadura civil-militar e a Democracia no Paraná, foi desenvolvido um instrumento composto de 2 (duas) partes: a primeira continha duas fontes iconográficas: uma publicada em 02/03/2015, no site Outras Linhas retrata um protesto realizado em Chapecó SC., onde aparece um cartaz com a frase: Intervenção militar já. Só o povo nas ruas tem poder! (COMERCIANTES..., 2015)

Outra, publicada no site Éoqa Bancários no dia 30/05/2015, demonstra o massacre desencadeado pela Polícia Militar do Paraná contra professores no dia 29/04/2015 na Praça Nossa Senhora de Salete, local em frente ao Palácio do Governo do Paraná na cidade de Curitiba (PROFESSORES..., 2015).

A segunda, uma ficha contendo o nome e uma questão: $A$ partir das fontes iconográficas apresentadas escreva uma narrativa sobre a Ditadura civil-militar e a Democracia no Paraná?

Após o preenchimento e recolhimento da ficha, iniciou-se o processo de análise e categorização dos conhecimentos apresentados pelos estudantes em suas narrativas, os quais são apresentados no gráfico a seguir:

Gráfico 1 - Categorização dos conhecimentos apresentados nas narrativas 


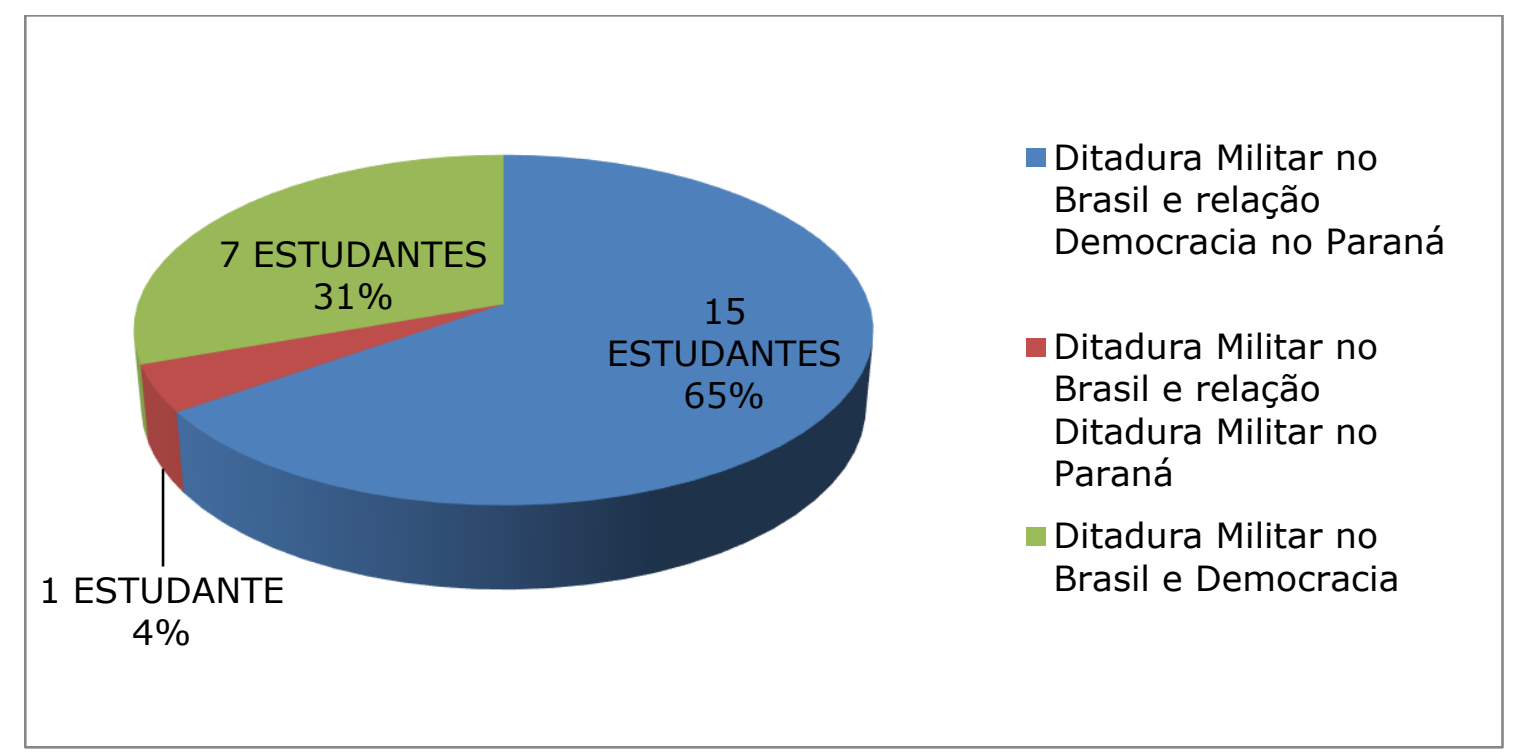

Fonte: O autor.

A partir do gráfico sobre os conhecimentos apresentados pelos estudantes em suas narrativas sobre a Ditadura civil-militar e a Democracia no Paraná, ficou constatado que 15 (quinze) estudantes fizeram relação entre Ditadura Militar no Brasil e Democracia no Paraná como podemos observar nas narrativas a seguir:

A ditadura teve fim há alguns anos, onde não se podia fazer críticas ao governo e ninguém tinha liberdade de expressão, ou então eram repreendidos, porque os militares acreditavam que $o$ povo que tinha voz era uma ameaça às autoridades. A qual se fez ligação com os atuais protestos dos trabalhadores de cargos públicos do estado do Paraná, onde os protestantes, que acreditam numa democracia, estão sendo repreendidos por mostrar a voz e lutar pelos seus direitos como cidadãos. Aí entra o tal questionamento: vivemos ou não em um país democrático? A ditadura acabou mesmo ou o povo ainda se reprime diante das autoridades? (J. T., grifo nosso).

Ditadura militar, é onde os militares tem o poder do país. Com experiências passadas no Brasil, foi uma época em que o povo não podia expressar sua opinião, quem não aceitasse as normas impostas pelos militares era perseguido, torturado e até morto. Esse modo de governo no geral é alcançado através de um golpe. No Paraná no dia 29/04 não se teve uma democracia, pois a votação foi fechada para o público, e lá na ALEP é considerada 'a casa do povo'. Com o uso da violência contra os manifestantes, ordens chegaram para a polícia de fazer o que for preciso para impedir a manifestação dos professores. Está na lei que servidores públicos tem o direito de fazer protestos. O governador Beto Richa está sendo considerado o culpado deste massacre. (L.T., grifo nosso). 
Ditadura civil-militar é um sistema político que foi aplicado no Brasil em 1964 e terminou em 1985. Nesse período de tempo o povo viveu com medo, não podia se expressar opiniões contra o governo, e se isso viesse a acontecer a pessoa era presa e torturada pelos militares. A relação entre a ditadura militar e a democracia no Paraná é que como na ditadura o povo perdeu a voz, agora o professor perdeu a voz também, eles foram lutar pelos seus direitos e acabaram sendo presos e torturados (jogaram bombas e balas de borracha). (C. L., grifo nosso).

A relação Ditadura Militar no Brasil e Democracia foi citada por 7 (sete) estudantes:

NA ditadura militar foi uma época muito censurada e violenta. Quem era contra as propostas de governo rapidamente era preso para prestar 'depoimento' e nunca mais eram vistos ou encontrados mortos, muito poucos sobreviveram as DOPS. A democracia nascida na antiga Grécia e aprimorada pela sociedade, não funciona como deveria, principalmente no Brasil (N. L., grifo nosso).

A ditadura civil-militar que vigorou após o golpe de 1964. É um grande erro o que está acontecendo sobre as manifestações no caso a 'democracia' sendo violentada pelos civis quererem os seus direitos. Polícia militar faz apenas o que o governo manda, caso contrário serão demitidos. Se os militares tomarem conta, o povo vai ser totalmente prejudicado, pois não haverá mais democracia (N. L., grifo nosso).

Na ditadura onde o exército fica no comando, onde o povo está contra ele tenta mudar sua forma de governo para uma democracia. Nossa democracia não está muito certa, pois o dinheiro não está indo para a mão de todos e o salário é o direito do povo ter (G. A., grifo nosso).

Somente 1 (um) estudante relacionou a Ditadura militar no Brasil com a Ditadura Militar no Paraná,

A ditadura civil-militar foi um período no qual os militares tomaram o poder e governaram o país. Eles exerciam os poderes e determinavam leis, e quando o povo se opunha, eles utilizavam a força para intervir, afinal 'não havia o que discutir com o governo'. Com relação ao Paraná, aconteceu igualmente aos outros estados do Brasil (V. P., grifo nosso).

Com o processo de categorização ficaram evidentes duas questões: a primeira está relacionada ao conceito Ditadura militar e Ditadura civil-militar, e a 
segunda com a Ditadura no Paraná, já que somente um estudante fez menção, ainda que timidamente.

Como forma de oportunizar o reconhecimento e a reflexão sobre as narrativas apresentadas nas fichas, a problematização sobre a temática A Ditadura Civil-Militar e a Democracia no Paraná foi realizada em sala de aula, nesta etapa do trabalho esse momento é importante "para que se dê um início de conflito cognitivo quando 0 aluno começa a confrontar as várias interpretações dadas por ele e seus colegas" (FERNANDES, 2007, p. 7).

\section{Propostas de intervenção}

A intervenção pedagógica foi problematizada por meio de diferentes perspectivas historiográficas buscando demonstrar aos estudantes que a História é constituída por interesses e interpretações.

Sobre a questão conceitual Ditadura militar e Ditadura civil-militar a intervenção pedagógica pautou-se em dois artigos que discutem a temática de forma antagônica (divergente), o primeiro publicado na Revista de História da Biblioteca Nacional com o título $O$ sol sem peneira: o apoio da sociedade civil foi fundamental para a longa vida da ditadura militar no Brasil do professor Titular de História Contemporânea da UFF Daniel Aarão Reis, segundo ele:

É inútil esconder a participação de amplos segmentos da população no movimento que levou à instauração da ditadura em 1964. É o mesmo que tapar o sol com a peneira. As Marchas da Família com Deus pela Liberdade mobilizaram dezenas de milhões de pessoas, de todas as classes sociais, contra o governo João Goulart (REIS, 2012, p. [1]).

O segundo, publicado no site Brasil de Fato com o título Virou moda o emprego da expressão "Ditadura Civil-Militar" para designar o regime instaurado em nosso país por meio do golpe militar de março-abril de 1964 do Jornalista e editor da Revista Adusp, Pedro Estevam da Rocha Pomar para ele

[...] renomear o período, trata-se de um profundo equívoco. Tivemos neste país não uma "Ditadura Civil-Militar", mas uma Ditadura Militar, sem aspas. Embora todos nós da esquerda 
saibamos da participação civil tanto no golpe de 1964 (fartamente documentada em livros com 1964: A Conquista do Estado, de René Dreyfuss) como no regime que dele se originou, também entendíamos perfeitamente que quem mandou de fato, quem exerceu o poder político, foi o Alto Comando das Forças Armadas. (POMAR, 2015, p. [1]).

Sobre o período da Ditadura no Paraná foram apresentados três documentários, o primeiro com o título Memórias da Repressão (1991), produzido em 1991 pela Secretaria de Comunicação Social do Paraná e digitalizado pelo Departamento Estadual de Arquivo Público.

Para contar um pouco a história da Universidade Federal do Paraná e a participação de professores e do movimento estudantil contra o governo militar no período de 1964 a 1985 foi exibida a terceira parte do documentário Oitenta anos de Resistência de 1992.

Por último foi apresentada a segunda parte de Tortura no Paraná (2013), exibido no Programa Meu Paraná, onde mostra alguns locais da cidade de Curitiba que teriam sido utilizados pelo governo militar para prender e torturar e depoimentos de ex-presos políticos paranaenses relatando um pouco da história desse período.

Para finalizar o processo de intervenção foram apresentados os artigos $1^{0}$ e $08^{\circ}$ da Constituição da República Federativa do Brasil de 1967, o Ato Institucional no 5 de 13 de dezembro de 1968, o Título I e o Capítulo II (Art. 60, Art. 90, Art. 10) e o Capítulo IV (Art. 14) da Constituição Federativa do Brasil de 1988.

\section{Produção de narrativas: elaboração de vídeos}

Após o processo de intervenção, foi solicitado aos estudantes que formassem pequenas equipes compostas de quatro (4) componentes para a elaboração de um roteiro e produção de um documentário com duração de um (1) a cinco (5) minutos para ser apresentado e discutido em sala de aula.

O prazo para a entrega do roteiro e da produção fílmica foi de duas (2) semanas e o resultado final dos trabalhos foi apresentado em sala de aula e em 
um seminário sobre $A$ importância do trabalho com fontes históricas, aberto aos demais estudantes da instituição de ensino.

\section{A ação dos sujeitos e a relação com o presente e com a sua vida prática}

Após o processo de intervenção por meio de fontes históricas diversificadas, das apresentações dos pequenos vídeos documentários e discussões em sala de aula, busquei entender se os estudantes perceberam os interesses presentes nos conceitos, Ditadura militar e Ditadura civil-militar, como eles discutiam esta forma de governo e como eles relacionavam com a questão Democracia no Paraná.

Para tanto foi confeccionada uma nova ficha com a questão: $A$ partir do trabalho com as fontes históricas e dos documentários produzidos e apresentados pelos colegas elabore uma narrativa sobre este período.

Após o preenchimento, as fichas foram recolhidas e iniciou-se novamente o processo de análise e categorização das narrativas buscando verificar se parte dos objetivos teriam sido atingidos, ou seja, se os estudantes conseguiram entender os interesses contidos nos conceitos de Ditadura militar e Ditadura civil-militar e que o Paraná também sofreu com esse período autoritário e repressivo.

Sobre os conceitos e a relação com Paraná

Ditadura civil-militar no Paraná é chamada civil-militar pelo fato do apoio do povo para que os militares assumissem o poder. Tanto no Paraná quanto em outros estados do Brasil, o regime ditatorial foi marcado pela repressão aos opositores e pelos que conspiravam contra o governo. 0 povo paranaense lutou contra essas repressões com tanta notoriedade como São Paulo e Rio de Janeiro o fizeram (H. T., grifo nosso).

Na minha opinião foi apenas uma ditadura militar por mais que os civis tenham apoiado a entrada do governo militar, a sociedade não teve representatividade nas decisões durante esse período. Além disso o estudo mais voltado ao Paraná, mostrou que se tratou de muito rigor com operações a qual temos testemunhas ainda hoje em dia (C. V., grifo nosso). 
Outra questão levantada é que alguns estudantes demonstraram mudanças na maneira de pensar historicamente interpretando as fontes, articulando temporalidades e dando um significado na vida prática a esses acontecimentos, como percebemos nas narrativas apresentadas:

Como vimos nas fontes mostradas pelo professor e a pesquisa que fizemos sobre a ditadura militar, vimos que ela realmente aconteceu efetivamente no Paraná mas, como nosso estado tem uma 'menor importância' em relação a estados como São Paulo e Rio de Janeiro, a ditadura aqui não foi amplamente divulgada. Naquela época, as pessoas não tinham nem vez nem voz. Eram submetidas ao estado e se 'demonstrassem' contrariedade ou oposição a ele, corriam o risco de ir parar na cadeia ou até pior, serem mortas. Após a queda da ditadura e a formulação de nova Constituição o poder do livre arbítrio e da liberdade de expressão foram reincorporadas. Os cidadãos voltaram a eleger seus representantes que tem por função criar leis que os beneficiem. Entretanto, essa liberdade de expressão criou um problema. As pessoas se expressam toda hora sem conteúdo, sendo influenciadas pela cultura de massa. Pessoas sem conteúdo elegem pessoas sem conteúdo que formam um país sem conteúdo (A. B., grifo nosso).

Com relação à Democracia no Paraná, a estudante J. T. faz uma crítica:

\begin{abstract}
A partir da Ditadura, vemos que a democracia atual não tem muita diferença da mesma, já que na época a repressão por liberdade de expressão era grande e violenta. Nas últimas manifestações, vimos que no Paraná as coisas não foram diferentes, pois os policiais agiram de forma bruta para com os professores, não deixando eles se expressarem (J. T., grifo nosso).
\end{abstract}

Como pudemos perceber, os instrumentos de metacognição, quando abordados a partir de conteúdos específicos, podem nos trazer respostas dando "indicativos do que ensinar, como ensinar, como o aluno apreende e interpreta as diversas narrativas" (FERNANDES, 2007, p. 4).

\title{
Considerações finais
}


Este trabalho de pesquisa visou por meio do aporte teórico e metodológico da Educação Histórica privilegiar os conhecimentos que os estudantes traziam para o ambiente escolar, levando-os a participarem do processo de análise e de interpretação das fontes históricas, criando novas perspectivas estabelecendo relações e encontrando significados.

Nesse sentido, algumas considerações podem ser apontadas, no que diz respeito aos conceitos Ditadura civil-militar e Ditadura militar houve mudanças tanto conceituais quanto de interpretação, pois as narrativas analisadas, após o processo de intervenção, apresentaram elementos que discutiam os interesses contidos nessas concepções.

Sobre o período em que o Paraná foi governado pelos militares, os estudantes refletiram a respeito da imagem que constroem dele e de seus habitantes relacionando o conceito de democracia problematizado em alguns Títulos, artigos e capítulos da Constituição da República Federativa do Brasil de 1967, do Ato Institucional de 1968 e da Constituição Federativa do Brasil de 1988 com o massacre ocorrido no dia 29 de abril de 2015 na cidade de Curitiba PR.

A partir de tais considerações pode-se pensar que, discutir evidências, problematizar conceitos, levantar hipóteses e produzir conhecimentos são elementos que constituem a construção do pensamento histórico e da formação da consciência histórica, características que foram demonstradas pelos estudantes neste trabalho desenvolvido em sala de aula.

\section{Referências}

BRASIL. Ato Institucional no 5, de 13 de dezembro de 1968. São mantidas a Constituição de 24 de janeiro de 1967 e as Constituições Estaduais; O Presidente da República poderá decretar a intervenção nos estados e municípios, sem as limitações previstas na Constituição, suspender os direitos políticos de quaisquer cidadãos pelo prazo de 10 anos e cassar mandatos eletivos federais, estaduais e municipais, e dá outras providências. Brasília: Presidência da República, 1968. Disponível em: http://www.planalto.gov.br/ccivil_03/ait/ait-05-68.htm. Acesso em: 20 maio 2015. 
BRASIL. Constituição. Constituição da República Federativa do Brasil de 1967. Brasília: Presidência da República, 1967. Disponível em: http://www.planalto.gov.br/ccivil_03/constituicao/constituica067.htm. Acesso em: 20 maio 2015.

BRASIL. [Constituição (1988)]. Constituição da República Federativa do Brasil. 27. ed. São Paulo: Saraiva, 1991.

COMERCIANTES de Joaçaba e Chapecó paralisam em protesto a impostos e pedem intervenção militar. Outras linhas, Chapecó, 2 mar. 2015. Disponível em: http://www.outraslinhas.com.br/?r=site/noticia\&id=878\#.VVU1ZflVik>. Acesso em: 13 maio 2015.

DEPARTAMENTO ESTADUAL DE ARQUIVO PÚBLICO. DOPS: série pastas temáticas 1937-1989. Disponível em: http://www.arquivopublico.pr.gov.br/modules/conteudo/conteudo.php?conteudo $=79$. Acesso em: 19 maio 2015 .

FERNANDES, Lindamir Zeglin. A reconstrução de aulas de história na perspectiva da educação histórica: da aula-oficina à unidade temática investigativa. [S. I.]: PDE, $2007 . \quad$ Disponível em: http://www.educadores.diaadia.pr.gov.br/modules/conteudo/conteudo.php?cont eudo=848\# historia. Acesso em: 10 abr. 2015.

GERMINARI, Geyso Dongley. A história da cidade, consciência histórica e identidade de jovens escolarizados. 2010. Tese (Doutorado em Educação) Universidade Federal do Paraná, Curitiba, 2010.

LEE, Peter. Em direção a um conceito de literacia histórica. Educar em Revista, Curitiba, p. 131-150, 2006. Edição especial.

MEMÓRIAS da Repressão. Direção: Rolando Acosta. Produção: Antônio Augusto. [Curitiba: Arquivo Público], 1991. 1 vídeo (17min10). Disponível em: http://www.arquivopublico.pr.gov.br/modules/conteudo/conteudo.php?conteudo =79. Acesso em: 19 maio 2015 .

OITENTA anos de resistência: a História da UFPR, terceira parte. Direção e roteiro: José Wille. Produção: Jussara Locatelli; Fernanda Morini. [Curitiba: UFPR], 1992. 1 vídeo (10min16). Disponível em: https://www.youtube.com/watch?v=OXHhuEAuSmg. Acesso em: 19 maio 2015.

POMAR, Pedro Estevam da Rocha. Virou moda o emprego da expressão "ditadura civil-militar" para designar o regime instaurado em nosso país por meio do golpe militar de março-abril de 1964. Brasil de fato, São Paulo, 2015. Disponível em: http://www.brasildefato.com.br/node/10300. Acesso em: 19 maio 2015.

PROFESSORES moverão ação criminal contra Beto Richa: sindicato da categoria responsabiliza governador tucano, secretário de Segurança e preșidente da Alep por "massacre" que deixou cerca de 200 feridos em Curitiba. Éoqa bancários, Curitiba, 30 maio 2015.2 Disponível em: http://www.bancarios.net.br/news/11066. Acesso em: 13 maio 2015. 
REIS, Daniel Aarão. O sol sem peneira: o apoio da sociedade civil foi fundamental para a longa vida da ditadura militar no Brasil. Revista de História da Biblioteca Nacional, Rio de Janeiro, ago. 2012. Disponível em http://www.revistadehistoria.com.br/secao/capa/o-sol-sem-peneira. Acesso em: 19 maio 2015.

RÜSEN, Jörn. Aprendizado histórico. In: SCHMIDT, Maria Auxiliadora; BARCA, Isabel; MARTINS, Estevão de Rezende (org.). Jörn Rüsen e o ensino de história. Curitiba: Ed. UFPR, 2011. p. 41-50.

RÜSEN, Jörn. Historical narration: foudation, types, reason. In: RÜSEN, Jörn. Studies in metahistory. Pretoria: Human Sciences Research Council, 1993.

RÜSEN, Jörn. Teoria da história: uma teoria da história como ciência. Tradução de Estevão C. de Rezende Martins. Curitiba: Editora da UFPR, 2015.

SCHMIDT, Maria Auxiliadora. Cognição histórica situada: que aprendizagem histórica é esta. In: SCHMIDT, Maria Auxiliadora Schmidt; BARCA, Isabel (org.). Aprender história: perspectivas da educação histórica. Ijuí: Unijuí, 2009. p. 2151.

SCHMIDT, Maria Auxiliadora Moreira dos Santos; Silva, Maria da Conceição; CAINELLI, Marlene. Educação Histórica e ensino de História: uma comunidade de investigadores - seus caminhos e desafios. In: SCHMIDT, Maria Auxiliadora Moreira dos Santos; Silva, Maria da Conceição; CAINELLI, Marlene (org.). Formação e aprendizagem: caminhos e desafios para a pesquisa em Educação Histórica e ensino de História. Goiânia: Editora Trilhas Urbanas, 2019. p. 09-22.

SCHMIDT, Maria Auxiliadora. Jörn Rüsen e sua contribuição para a didática da história. Intelligere: revista de historia intelectual, São Paulo, v. 3, n. 2, p. 6076, set./dez. 2017. Disponível em: http://www.revistas.usp.br/revistaintelligere/article/view/127291/136217. Acesso em: 21 dez. 2017.

SCHMIDT, Maria Auxiliadora; CAINELLI, M. Ensinar história. São Paulo: Scipione, 2004.

TORTURA no Paraná: parte 2 (Ditadura Militar). Gehad Hajar. [S. I.: s. n.], 2013. 1 vídeo (14min25). Disponível em: https://www.youtube.com/watch?v=oLzAWRGAbdM. Acesso em: 13 maio 2015. 